\title{
PREPARATION AND APPLICATION OF MONOCLONAL ANTIBODY TO SUGARCANE (SACCHARUM L. SPP. HYBRIDS) SOP5CS PROTEIN
}

\author{
LI, J. ${ }^{1}-$ WANG, L. R. ${ }^{1}-$ HUANG, X. ${ }^{2}-$ XING, Y. X. ${ }^{1}-$ YANG, L. T. ${ }^{*}-$ LI, Y. R..$^{2 *}$ \\ ${ }^{1}$ College of Agriculture, Guangxi University, Nanning 530005, China \\ ${ }^{2}$ Key Laboratory of Sugarcane Biotechnology and Genetic Improvement (Guangxi), Ministry of \\ Agriculture and Rural Area; Guangxi Key Laboratory of Sugarcane Genetic Improvement; \\ Sugarcane Research Center, Chinese Academy of Agricultural Sciences-Guangxi Academy of \\ Agricultural Sciences, Nanning 530007, China \\ *Corresponding authors \\ e-mail: litao61@hotmail.com (L.T. Yang), liyr@gxaas.net (Y.R. Li)
}

(Received $5^{\text {th }}$ May 2019; accepted $16^{\text {th }}$ Jul 2019)

\begin{abstract}
Delta^{1}$-pyrroline-5-carboxylate synthase (P5CS) is a key enzyme in proline biosynthesis. In this study, the nucleotide sequence of sugarcane P5CS (SoP5CS) gene was obtained from sugarcane. Then the ORF of SoP5CS linked with pET-30a vector and the SoP5CS protein was expressed successfully in $E$. coli by the induction of $1.0 \mathrm{mM}$ IPTG at $28^{\circ} \mathrm{C}$ for $6 \mathrm{~h}$. The prokaryotic expression protein was expressed as inclusion bodies (IBs). It was purified by Ni- NTA Resin firstly and then refolded, dialyzed and further purified by gel filtration. The monoclonal antibody of SoP5CS was prepared using mice. The expression of SoP5CS gene and the corresponding protein and physiological parameters associated with drought resistance were detected in sugarcane leaves under different drought stresses, they worked together to regulate the drought resistance process of sugarcane. This is the first report on the preparation of P5CS monoclonal antibody and the expression of the antibody in sugarcane, which would provide new methods to study the function of SoP5CS response to various abiotic stresses and other aspects.
\end{abstract}

Keywords: sugarcane, P5CS gene; proline, monoclonal antibody, physiological index

Abbreviations: ABA: Abscisic acid; CAT: Catalase; cDNA: Complementary DNA; DTT: Dithiothreitol; ELISA: Enzyme-linked immunosorbent assay; IBs: Inclusion bodies; IPTG: Isopropyl- $\beta-D-$ thiogalactopyranoside; LB: Luria-Bertani; MDA: Maleic dialdehyde; ORF: Open reading frame; P5CS: $\Delta^{1}$-pyrroline-5-carboxylate synthase; PBS: Phosphate buffer saline; PCR: Polymerase chain reaction; POD: Peroxidase; ROS: Reactive oxygen species; RWC: Relative water content; SDS-PAGE: Sodium dodecyl sulfate polyacrylamide gel electrophoresis; So: Saccharum officinarum; SOD: Superoxide dismutase

\section{Introduction}

Proline plays an important role in plant osmotic adjustment processes, and it is a penetration protective agent, protein stabilizer and free-radical scavenger (Kishor et al., 2005). Studies have shown that the accumulation of proline showed a positive correlation with stress adaptation of drought and salt in plants (Kishor et al., 1995). In normal conditions, proline is synthesized mainly by ornithine pathway, whereas it is made directly through the glutamate pathway under stress conditions (Delauney et al., 1993). P5CS is a bifunctional enzyme and catalyzes the first two steps of glutamate pathway (Kishor et al., 1995).

In plants, the activity of P5CS was assayed in duckweed under gradually increasing cadmium stress (Qiao et al., 2015), and in Arabidopsis thaliana under salt tolerance (Saibi et al., 2015). More researches concentrated on the P5CS gene, which has been 
isolated from many plants, such as cowpea (Hu et al., 1992), alfalfa (Ginzberg et al., 1998, barley (Romman et al., 2011), sorghum (Su et al., 2011), Chinese wolfberry (Guan et al., 2014); Nitraria tangutorum (Zheng et al., 2014), mulberry (Zhou et al., 2016), and others. The expression of P5CS gene was analyzed by RT-PCR under salt stress (Ortega et al., 2008), Northern blotting under drought (Porcel et al., 2004), salt (Do et al., 2003) stress and qRT-PCR (Jain et al., 2015) under drought stress. And previous research showed that drought stress could induce the changes in gene and protein expression and physiological parameters associated with drought resistance (Kuzuoglu-Ozturk et al., 2012; Dey et al., 2016; Wang et al., 2016; Cao et al., 2017).

Monoclonal antibody is widely employed in the detection and identification of protein in plants by Western blotting and enzyme-linked immunosorbent assay (ELISA). The former is widely used in studying the expression of a protein in different plant tissues (Pereira et al., 2005), under various stresses (Pruvot et al., 1996; Ozturk et al., 2012). Most reports have been focusing on transgenic plants accumulation of a foreign protein resistant to virus (Yu et al., 2011), disease (Maruthasalam et al., 2007), pest (McManus et al., 1999), abiotic stress (Subramanyam et al., 2012) and so on.

To our knowledge, there have not been any reports about P5CS monoclonal antibody in plants. Sugarcane (Saccharum L. spp. hybrids) is the most important sugar crop and one of the main agricultural commodities in the world. Guangxi is the largest sugarcane producing areas in China, however, about $80 \%$ of the sugarcane is planted in upland areas with shallow tillage layer and no irrigation system, so drought is a main constraint factor for sugarcane production (Li and Yang, 2015). The purpose of this study was to prepare monoclonal antibody of sugarcane P5CS gene to provide a reference for further study on the mechnism of sugarcane resistance to drought stress.

\section{Materials and methods}

\section{Sugarcane material and treatments}

The sugarcane variety GT 21 was used as plant material, and the single bud cane setts were planted in sand. After the seedlings grew to 3-4 leaves, they were transplanted to plastic pots containing sand and soil with the ratio of 1:2 for culturing. When the seedlings grew to 7-8 leaves, the consistent plants were selected for drought treatment, that is, the plants were subjected to withholding water and the control plants were well-watered. The leaf samples were collected from leaf +1 (top visible dewlap leaf) at $0,1,3,5$ and $7 \mathrm{~d}$, respectively, after drought treatment. There were three replications for each treatment and all the samples were wrapped in aluminum foil, placed in liquid nitrogen and stored at $-80{ }^{\circ} \mathrm{C}$.

\section{Experiment reagents}

The Trizol reagent and anti $\beta$-Actin mouse monoclonal antibody were bought from Beijing ComWin Biotech Co., Ltd. (Beijing, China); EcoR I and Xho I restriction enzymes and RevertAid First Strand cDNA Synthesis Kit were bought from Thermo Fisher Scientific (Shanghai, China); PMD18-T vector and DNA Ligation Kit were got from TaKaRa Company (Dalian, China). Escherichia coli DH5 $\alpha$ and BL21 (DE3) were bought from TransGen Biotech (Beijing, China). Protein A Sefinose ${ }^{\mathrm{TM}}$ Kit, Ni-NTASefinose Column, Sefinose ${ }^{\mathrm{TM}}$ CL-6B and Non-Interference Protein Assay Kit were products of Sangon Biotech Company (Shanghai, China). pET-30a was kept by the 
laboratory. All other chemicals were obtained from commercial sources and analytical grade.

\section{Isolation of SoP5CS}

Total RNA of sugarcane leaves was extracted and tested the concentration and integrity by Implen P 300 NanoPhotometer and 1\% agarose gel electrophoresis. The cDNA for gene cloning was synthesized using RevertAid First Strand cDNA Synthesis Kit. Based on the sugarcane P5CS gene sequences in GenBank (Accession No. Eu005373), the primers of upstream and downstream for both sides of its largest open reading frame $(2148 \mathrm{bp})$ designed with Primer Premier 5.0 software are 5'TCAGAATTCATGGCCACCGTGGACCGGACC-3', and 5'-TGTCTCGAGTTGCAAAGGAAGGTTCTTATG-3', respectively, that EcoR I and Xho I restrict enzyme sites are underlined. The PCR products were purified and cloned into PMD18-T vector and sequenced on both strands in Beijing Genomics Institute (Shenzhen, China).

\section{Prokaryotic expression, extraction and purification of SoP5CS protein}

The pET-30a was used as the prokaryotic expression vector. The plasmids of recombinant strain PMD-SoP5CS and pET-30a were extracted and double digested with $E c o$ R I and Xho I. Then SoP5CS and the vector fragments were ligated and transformed into the E. coli BL 21 (DE 3) cells. The recombinant plasmid was detected by PCR and sequenced (The Beijing Genomics Institute, Shenzhen), and verified by double enzymes digestion. The recombinant strain was incubated in liquid LB medium (contained 100 $\mathrm{mg} / \mathrm{L}$ kanamycin) until the value of OD 600 reached $0.4-0.6$, and the target protein was induced with $1.0 \mathrm{mM}$ IPTG for an additional $6 \mathrm{~h}$. The cell pellets were collected by centrifugation and resuspended in lysis buffer $\left(500 \mathrm{mM} \mathrm{NaCl}, 50 \mathrm{mM} \mathrm{NaH}_{2} \mathrm{PO}_{4}\right.$, and 10 $\mathrm{mM}$ imidazole, $\mathrm{pH} 8.0$ ), then lysed by sonication (pulse $5 \mathrm{~s}$, pause $5 \mathrm{~s}, 20 \mathrm{~min}$ ) using an ultrasonic processor VCX 750 (Sonics \& Materials, Inc.). Then the cell lysate was centrifuged to precipitate the cellular debris and the supernatant was transferred to fresh microcentrifuge tubes for further purification using a Ni-NTA-Sefinose Column. Then the wash fractions were collected and analyzed by SDS-PAGE.

\section{Refolding, dialysis and concentration of SoP5CS protein}

The over expressed SoP5CS proteins were refolded under the buffer (PBS, $2 \mathrm{mM}$ DTT, $0.05 \%$ SKL, pH 7.4) and centrifuged, then the supernatant was collected and dialyzed for overnight at $4{ }^{\circ} \mathrm{C}$ with dialysis tubing cellulose membrane (MW 10,000 Da, Sigma). The proteins were further dialyzed twice with fresh dialysis buffer each time for $3 \mathrm{~h}$. The dialyzed proteins were analyzed by SDS-PAGE to confirm it remained intact and then purified by gel filtration using Sefinose ${ }^{\mathrm{TM}}$ CL-6B. Then the protein was concentrated by PEG 20000 and determined using the Non-Interference Protein Assay Kit.

\section{Preparation of monoclonal antibody}

Female BALB/c mice were immunized subcutaneously using conventional methods. The immunization was given 3 times with 2 week intervals after the first immunization. And the mice would have an ictus immunisatorius before the cell fusion. The antiserum was collected in 10 days after the last immunization and the SoP5CS antibody titer was 
determined by indirect ELISA. The mouse whose antiserum exhibited the highest value of the antibody titer was selected for the subsequent fusion. Splenocytes of selected mice were fused with $\mathrm{Sp} 2 / 0$ cells, then the fused cells were suspended and placed into a total of 96 wells cell culture plates under $5 \% \mathrm{CO}_{2}, 37^{\circ} \mathrm{C}$. Two weeks later, positive hybridomas were selected and subcloned. Supernatants from the positive wells were detected by indirect ELISA and the clones showed high titer and good condition were selected to generate ascites. Antiserum of selected mouse was reacted with different amounts of the purified SoP5CS protein to analyze the quality. For Western blotting, the dilution rate of SoP5CS antibody and goat anti-mouse antibody (Beijing ComWin Biotech Co., Ltd.) was 1:2000. The membrane was placed in FluorChem and HD2 (ProteinSimple) was exposed for 1-10 min for images captured by using electrochemiluminescence (ECL) substrate (PIERCE). Then the monoclonal antibodies were purified by using the protein A column and stored at $-80^{\circ} \mathrm{C}$.

\section{Application of monoclonal antibody}

After drought treatment, the leaves were sampled to detect the expression of SoP5CS gene and its encoded protein. Besides, the physiological parameters, including proline, maleic dialdehyde (MDA) and abscisic acid (ABA) contents, superoxide dismutase (SOD), catalase (CAT) and P5CS activities, relative water content (RWC) and Chlorophyll content (SPAD value) were also measured. Total proteins in sugarcane leaves were extracted with the method of Parrott et al. (2005) and qRT-PCR was used the method described by Niu et al. (2015). RWC of the leaves were calculated with the method of Kautz et al. (2015). SPAD value was measured as the method of Phan et al. (2016). Other physiological parameters (contents of proline, MDA and ABA, and activities of SOD, CAT and P5CS) were measured using ELISA Kit (ColorfulGene Biological Technology Co., Ltd., Wuhan, China).

\section{Statistical analysis}

The data were analyzed using the IBM SPSS Statistics 20 software and Excel 2013 (Microsoft). There were three replicates for each experiment, and statistical differences were compared based on the Duncan's test with P values set at 0.05 and 0.01 levels.

\section{Statement on ethical approval}

All experimental procedures were conducted in conformity with institutional guidelines for the care and use of laboratory animals in The Animal Experimental Center of Shanghai General Hospital, Shanghai, China, and conformed to the National Institutes of Health Guide for Care and Use of Laboratory Animals.

\section{Results}

\section{Construction of prokaryotic expression vector}

Bands of about $2150 \mathrm{bp}$ were obtained by RT-PCR (Fig. 1A) and they were recovered together and inserted into pMD-18T to get the recombinant plasmid pMDSoP5CS which showed a fragment of 2148 bp by sequencing. ORF of SoP5CS was ligated with pET-30a and the recombinant plasmid pET-SoP5CS was expressed in $E$. coli BL 21 (DE 3) and confirmed by double digested with EcoR I and Xho I. The result 
showed that the prokaryotic expression vector with SoP5CS gene pET-SoP5CS had been built successfully (Fig. 1B).

A

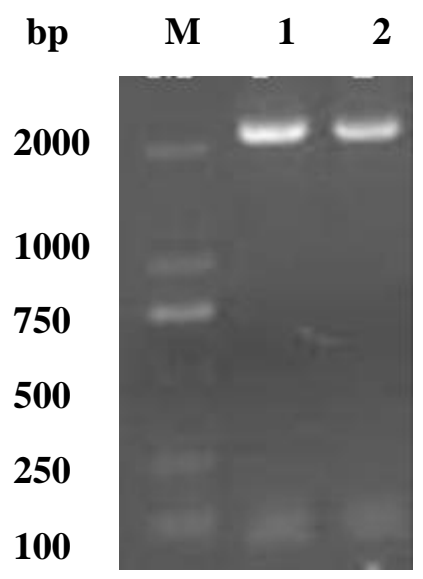

B

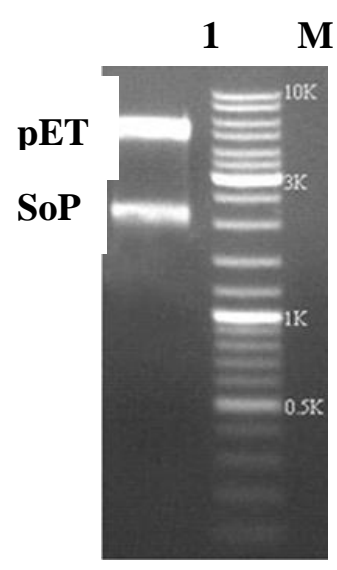

Figure 1. Amplification of SoP5CS and verification of recombinant plasmid. A Products of RTPCR from cDNA of sugarcane leave by. Lane 1-2, products of RT-PCR; Lane M, DNA marker. $\boldsymbol{B}$ Restriction enzymes digestion analysis of pET-SoP5CS plasmid. Lane 1, Products of double enzymes digestion. Lane M, DNA marker

\section{Expression, purification, AND concentration of SoP5CS protein}

The molecular weight of the fusion SoP5CS protein is $\sim 84 \mathrm{kDa}$ according to the sequences of pET-30a and ORF of SoP5CS. SDS-PAGE analysis revealed that the target protein was expressed only in the insoluble inclusion bodies (IBs) (Fig. 2A). Then the SoP5CS protein was purified using Ni-NTA Resin (Fig. 2B), the final product was refolded and dialyzed. After gel filtration, the pure SoP5CS protein was obtained (Fig. 2C). Then the protein was concentrated using PEG 20000 and a expected single band of $\sim 84 \mathrm{kDa}$ protein was observed (Fig. 2D). About $15 \mathrm{mg}$ of SoP5CS at the concentration of $1.37 \mathrm{mg} / \mathrm{ml}$ was obtained by the protein quantitative kit, and the purity was more than $90 \%$, which meet the requirement of preparing the monoclonal antibody.

\section{Titer and specificity analysis of SoP5CS antibody}

After fusion of immunized BALB/c mouse splenocytes and Sp2/0 mouse myeloma cells, cell supernatant was measured by indirect ELISA $\left(\mathrm{OD}_{450}\right)$. The cell lines with the highest positive value were selected and subcloned. Nine hybridoma cell lines that stably secreted SoP5CS McAb were obtained and they were 1E1, 3D10, 3H10, 5F8, 5E12, 4D6, 4F10, 5C10 and 2F11. The titer of 9 hybridoma cell lines was determined by indirect ELISA method (Table 1). Based on the growth state, the cell line of 4F10 was finally selected to collect the supernatant which was purified by Protein A Sefinose $^{\mathrm{TM}}$ Kit. The pure supernatant was reacted with different amounts of SoP5CS protein by Western blotting. The expected $84 \mathrm{kDa}$ in different brightness bands were detected with different amount of antigen (Fig. 3).

According to the growth state, the cells of 4F10 and 4F10E8 were selected to inject the mice, and the ascites was purified by Protein A Sefinose ${ }^{\mathrm{TM}}$ Kit. The concentration of monoclonal antibody was $2.15 \mathrm{mg} / \mathrm{ml}$ measured with UV spectrophotometer. The titer 
of the purified antibody was more than $64 \mathrm{k}$ analyzed by indirect ELISA method (Table 2), which met the requirement of Western blotting detection. Thus, the preparation of SoP5CS monoclonal antibody was successful and it is ready for further research.

A

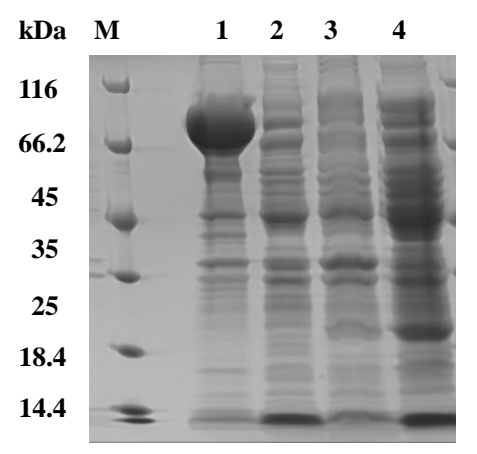

C

$\begin{array}{llllllllllllll}\mathrm{kDa} & \mathrm{M} & 1 & 2 & 3 & 4 & 5 & 6 & 7 & 8 & 9 & 10 & 11 & 12\end{array}$

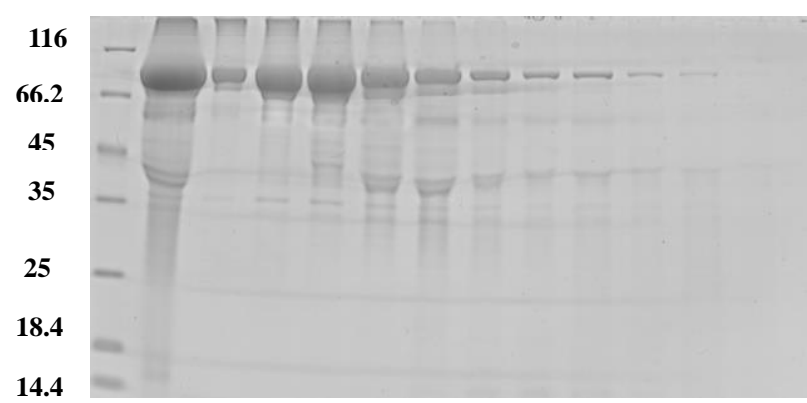

\section{B}

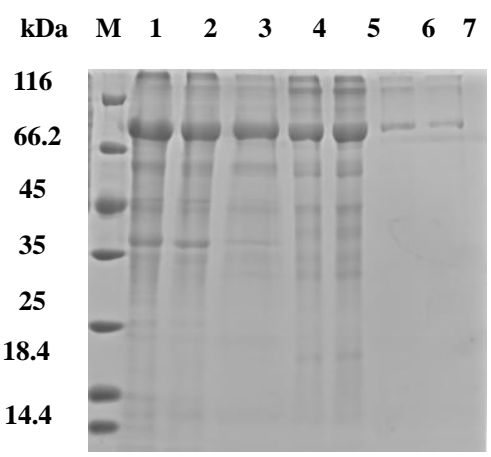

D

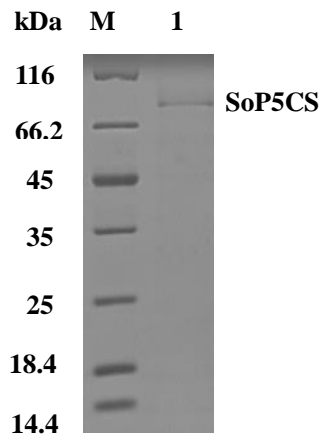

Figure 2. Analysis of SoP5CS protein expression, purification and concentration by SDS-PAGE from $p E T$-SoP5CS. A SoP5CS protein induced by $1.0 \mathrm{mM} \mathrm{IPTG.} \mathrm{Lane} \mathrm{1,} \mathrm{induced} 6 \mathrm{~h}, 28^{\circ} \mathrm{C}$

(Precipitant); Lane 2, induced $6 \mathrm{~h}, 28{ }^{\circ} \mathrm{C}$ (Supernatant); Lane 3, no IPTG (Precipitant); Lane 4, no IPTG (Supernatant); Lane M, protein Marker. B The protein purification by $\mathrm{Ni}^{2+}$ affinity chromatography. Lane 1, before loading; Lane 2, flow through; Lane 3, wash with $20 \mathrm{mM}$ imidazole; Lane 4-7, wash with $500 \mathrm{mM}$ imidazole; Lane M, protein marker. C The protein purified with gel filtration (Lane 1-12). D, SoP5CS protein concentrated (Lane 1)

Table 1. Titer determination of supernatant of selected hybridoma cell lines by ELISA

\begin{tabular}{c|c|c|c|c|c|c|c|c|c|c|c}
\hline \multirow{2}{*}{ Sample } & \multirow{2}{*}{+} & \multirow{2}{*}{$\boldsymbol{*}$} & \multicolumn{10}{|c}{ Dlank } & \multicolumn{10}{|c}{ Dilution rate } \\
\cline { 5 - 11 } & & & & $\mathbf{1 : 1}$ & $\mathbf{1 : 1 0 0}$ & $\mathbf{1 : 2 0 0}$ & $\mathbf{1 : 4 0 0}$ & $\mathbf{1 : 8 0 0}$ & $\mathbf{1 : 1 6 0 0}$ & $\mathbf{1 : 3 2 0 0}$ & $\mathbf{1 : 6 4 0 0}$ \\
\hline 1E1 & 1.176 & 0.035 & 0.062 & 0.643 & 0.438 & 0.287 & 0.172 & 0.096 & 0.081 & 0.052 & 0.049 \\
3D10 & 1.393 & 0.058 & 0.061 & 0.733 & 0.489 & 0.324 & 0.209 & 0.120 & 0.079 & 0.044 & 0.041 \\
3H10 & 1.385 & 0.048 & 0.056 & 0.630 & 0.421 & 0.279 & 0.158 & 0.095 & 0.077 & 0.064 & 0.034 \\
5F8 & 1.167 & 0.054 & 0.057 & 0.464 & 0.248 & 0.134 & 0.097 & 0.067 & 0.069 & 0.039 & 0.026 \\
5E12 & 0.958 & 0.137 & 0.053 & 0.343 & 0.222 & 0.125 & 0.081 & 0.049 & 0.051 & 0.050 & 0.049 \\
4D6 & 1.007 & 0.065 & 0.075 & 0.628 & 0.382 & 0.269 & 0.159 & 0.081 & 0.049 & 0.068 & 0.036 \\
4F10 & 1.769 & 0.046 & 0.057 & 0.517 & 0.342 & 0.207 & 0.124 & 0.066 & 0.049 & 0.037 & 0.030 \\
5C10 & 1.380 & 0.065 & 0.058 & 0.260 & 0.182 & 0.146 & 0.074 & 0.080 & 0.064 & 0.062 & 0.064 \\
2F11 & 1.129 & 0.064 & 0.075 & 0.454 & 0.312 & 0.215 & 0.156 & 0.114 & 0.095 & 0.065 & 0.068 \\
\hline
\end{tabular}

+: Positive control (the mouse serum before fusion). -: Negative control (the mouse serum before immunization). Blank: Antibody dilution buffer. The data are optical density values at $450 \mathrm{~nm}$ 
Table 2. Titer determination of monoclonal antibody by ELISA

\begin{tabular}{c|c|c|c|c|c|c|c|c|c|c}
\hline & + & - & \multirow{2}{*}{ Blank } & \multicolumn{7}{|c}{ Dilution rate } \\
\cline { 5 - 10 } & & & & $\mathbf{1 : 1 0 0 0}$ & $\mathbf{1 : 2 0 0 0}$ & $\mathbf{1 : 4 0 0 0}$ & $\mathbf{1 : 8 0 0 0}$ & $\mathbf{1 : 1 6 0 0 0}$ & $\mathbf{1 : 3 2 0 0 0}$ & $\mathbf{1 : 6 4 0 0 0}$ \\
\hline $\mathrm{OD}_{450}$ & 2.128 & 0.065 & 0.069 & 1.253 & 0.894 & 0.498 & 0.337 & 0.263 & 0.218 & 0.192 \\
\hline
\end{tabular}

+: Positive control (the mouse serum before fusion). -: Negative control (the mouse serum before immunization). Blank: Antibody dilution buffer

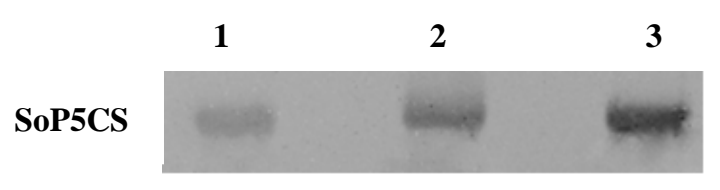

Figure 3. Specificity analysis of SoP5CS antibody by Western blotting assay. The supernatant of selected hybridoma cell reacted with different amounts of the SoP5CS protein. Lane 1-3, loaded 1, 2 and $4 \mu \mathrm{g}$ protein, respectively

\section{Expression of SoP5CS gene and its encoded protein in sugarcane under drought stress}

Under drought stress, the expression level of SoP5CS increased rapidly, reached the peak at $5 \mathrm{~d}$, which was 11.22-fold higher than that at $0 \mathrm{~d}$, and also maintained at high levels ( 5-fold) at 3 and $7 \mathrm{~d}$ (Fig. 4A). Endogenous SoP5CS proteins from sugarcane leaves under drought stress were detected by Western blotting and $\beta$-actin was used as the reference gene. A total of $25 \mu \mathrm{g}$ protein was loaded in each lane and the results (Fig. 4B, C) indicated that the relative expression levels of SoP5CS under drought stress were all higher than that in normal condition $(0 \mathrm{~d})$. But the expression level of SoP5CS protein increased slightly that were all below 2 -fold while compared to $0 \mathrm{~d}$, and the highest expression was at $7 \mathrm{~d}$ (1.99-fold).

A

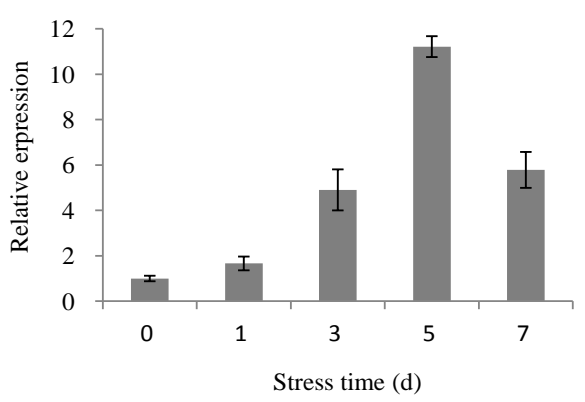

B

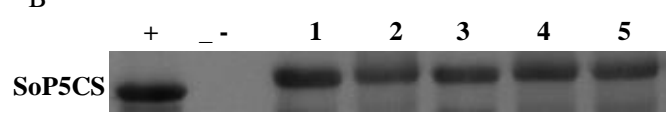

$\beta$-Actin
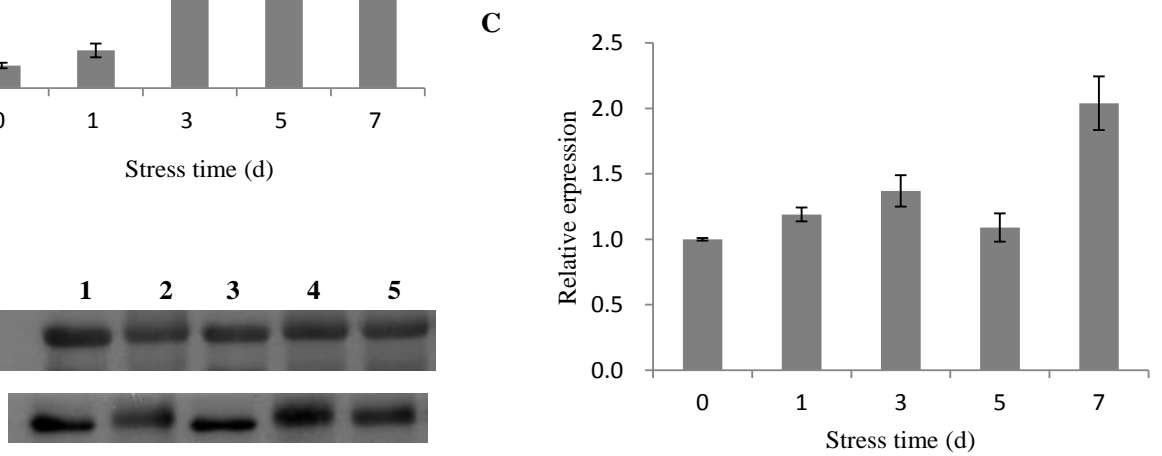

Figure 4. Relative expression of SoP5CS gene $(A)$ and its encoded protein $(B, C)$ in sugarcane leaves under drought stress. For Western blotting, the anti-SoP5CS antibody reacted with endogenous SoP5CS protein from sugarcane leaves under different drought stresses. Lane 1-6, 0, 1, 3, 5 and $7 d$ under drought stress, respectively; Lane +, purified SoP5CS protein; Lane -, sterile water. Whiskers indicate the standard deviation of three replicates 


\section{Physiological changes in sugarcane leaves under drought stress}

Under drought stress, contents of proline and MDA increased rapidly and reached the peak at $7 \mathrm{~d}$, and those at 1,3 and $5 \mathrm{~d}$ were also significantly higher than those of 0 day (Fig. 5A, C). ABA content increased slightly and also reached the peak at $7 \mathrm{~d}$ (Fig. 5B).

As shown in Figure 6A, there was no significant difference in SOD activity between normal condition $(0 \mathrm{~d})$ and $1 \mathrm{~d}$, while it was significantly higher at 3,5 and $7 \mathrm{~d}$. Drought stress treatments showed significantly higher CAT activity than that at $0 \mathrm{~d}$ (Fig. 6B). P5CS activity showed the trend of increase firstly and then decrease, which reached the peak at $3 \mathrm{~d}$ (Fig. 6C). Chlorophyll content and RWC decreased slightly firstly and then reduced markedly as the drought stresses were intensified (Fig. 7).

\section{Discussion}

There have been no literature reports on overexpression and purification of plant P5CS in E. coli yet, however, the prokaryotic expression vector of pET-30a has been used in different proteins from other plants (Wan et al., 2010; Zhu et al., 2012; Wang et al., 2015). In this research, the recombinant protein was expressed in E. coli as an inclusion body, but it takes long and intricate steps to form soluble proteins and it is difficult for purification (Nahálka et al., 2009). The formation of bacterial IBs is common due to an imbalance between protein deposition and removal (Carrio et al., 1999; Carrio and Villaverde, 2001). The concentration of IPTG, growth temperature and time may influence the expression pattern of recombinant protein (Sorensen and Mortensen, 2005; Montalbán et al., 2006). But in many cases, screening and optimization of these conditions still could not eliminate the formation of IBs (Sahdev et al., 2008; Xue et al., 2011). Although we made efforts to optimize the expression conditions, the recombinant protein still accumulated as IBs. The IBs of SoP5CS were firstly purified by Ni-NTA Resin and about $15 \mathrm{mg}$ purified SoP5CS was obtained from 1 liter of culture broth after refolding, dialysis, gel filtration and concentration. The yield of SoP5CS was not very high compared with other proteins purified from inclusion body (Ruan et al., 2016), but it was enough for further use.

Under drought stress, drought resistance genes could be induced. And previous research showed that the expression of P5CS gene was up-regulated under drought stress (Jain et al., 2015; Zhou et al., 2016; Wei et al., 2016), which was consistent with the results of our study. The expression of SoP5CS protein in different drought stresses was also up-regulated but showed lower expression quantity compared to the corresponding gene. In this study, distinct changes in physiological parameters associated with drought resistance were also detected. The increased activities of both SOD and CAT could protect sugarcane cells against reactive oxygen species (ROS). The free proline acts as a multifunctional osmolyte in plants and plays important roles in enhancing osmotic stress tolerance (Krasensky and Jonak, 2012). Higher activity of P5CS could help synthesize more proline that act as an osmoprotectant thus help tolerate drought stress. Endogenous ABA was also increased with the up-regulated of SoP5CS, thus SoP5CS may be involved in an ABA-dependent stress signaling pathway. Previous studies showed that accumulation of $\mathrm{ABA}$ was important for the regulation of P5CS expression and proline accumulation level in Lycium chinense (Guan et al., 2014). The up-regulated expression of SoP5CS gene and the corresponding protein and physiological changes in sugarcane leaves might work together to regulate the drought resistance process of sugarcane. 

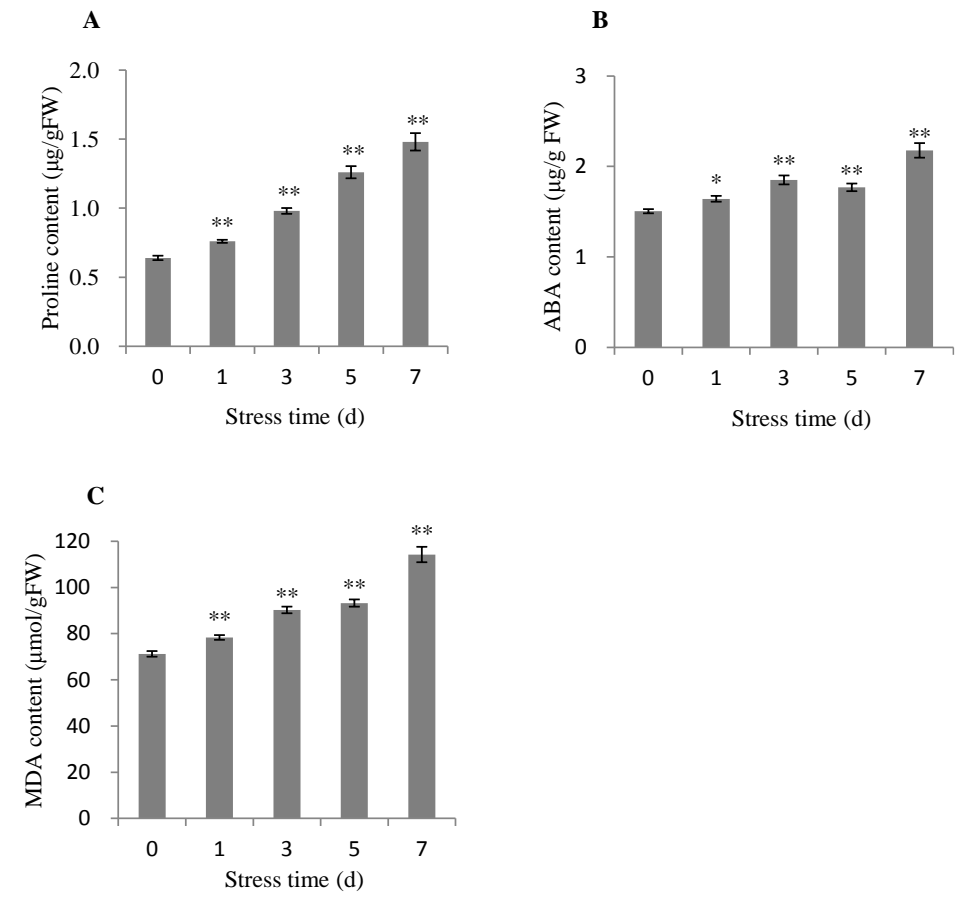

Figure 5. Contents of proline (A), $A B A(B)$ and $M D A(C)$ in sugarcane leaves under drought stress. All data are means $\pm S D$ calculated from three replicates. Symbols $*$ and $* *$ indicate significant difference between different drought stresses and normal condition $(0 \mathrm{~d})$ at 0.05 and 0.01 levels, respectively
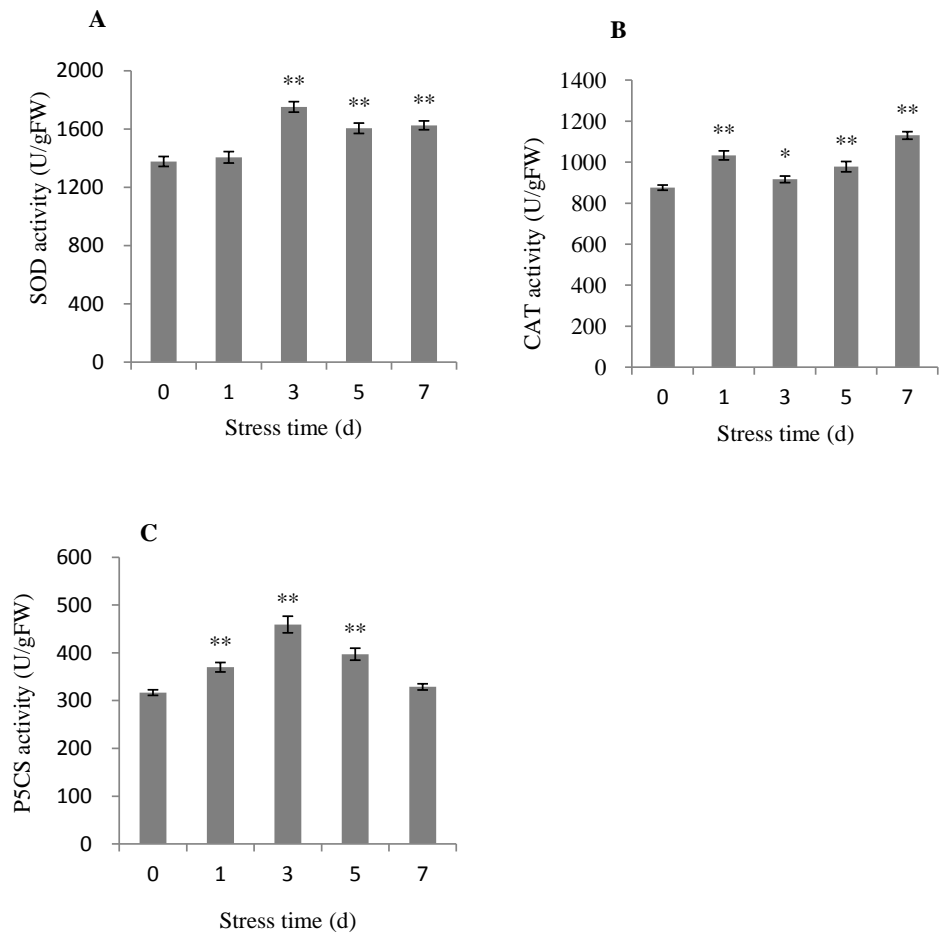

Figure 6. Activities of SOD (A), CAT (B) and P5CS $(C)$ in sugarcane leaves under drought stress. All data are means $\pm S D$ calculated from three replicates. Symbols $*$ and $* *$ indicate significant difference between different drought stresses and normal condition $(0$ d) at 0.05 and 0.01 levels, respectively 

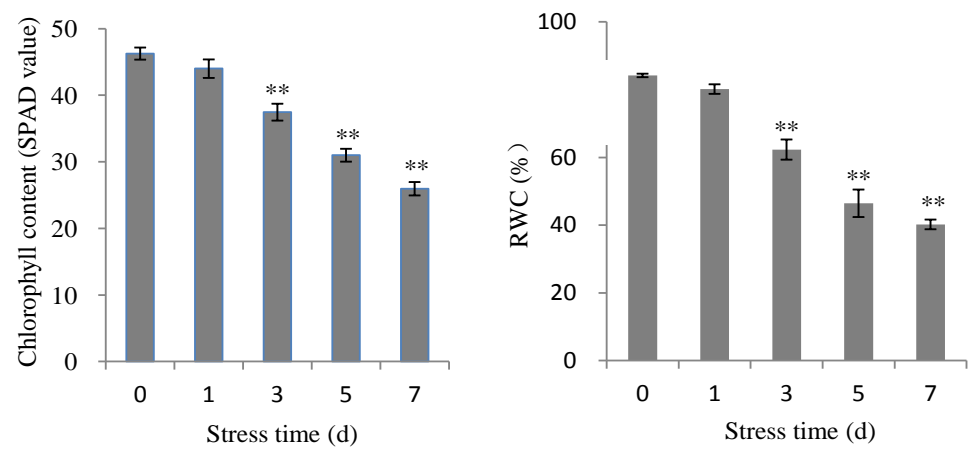

Figure 7. Chlorophyll content $(A)$ and RWC (B) in sugarcane leaves under drought stress. All data are means $\pm S D$ calculated from three replicates. Symbols $*$ and $* *$ indicate significant difference between different drought stresses and normal condition $(0 \mathrm{~d})$ at 0.05 and 0.01 levels, respectively

\section{Conclusion}

In this study, SoP5CS monoclonal antibody was prepared and the expression of SoP5CS protein and the corresponding gene and physiological parameters associated with drought resistance were detected in sugarcane leaves under drought stress. The SoP5CS monoclonal antibody obtained in the present study will be useful for further research on plant stress response, defense signaling pathways, and other aspects in plants. In future research, the function of SoP5CS could be identified by overexpression of SoP5CS protein not only in sugarcane but also in other plants. The preparation of SoP5CS monoclonal antibody could provide a new approach in research of the P5CS protein in plants.

Acknowledgments. This work was supported by the grants from International Cooperation Program Project of China (2013DFA3160), Guangxi Funds for Bagui Scholars and Distinguished Experts (2013), Guangxi Special Fund for Scientific Base and Talent (GKAD17195100), Guangxi Key Laboratory Fund (12-K-05-01) and Fund for Guangxi Innovation Teams of Modern Agriculture Technology (gjnytxgxcxtd-03).

Conflict of interests. The authors declare that they have no conflict of interest.

Author contribution. L. T. Y. and Y. R. L. designed the study. J. L. and L. R. W. conducted the experiments. J. L., L. R. W. and Y. X. X. analyzed data. J. L. L. T. Y. and Y. R. L. wrote the manuscript. L. T. Y. and Y. R. L. revised and finalized the manuscript.

\section{REFERENCES}

[1] Cao, Y., Luo, Q. X., Tian, Y., Meng, F. J. (2017): Physiological and proteomic analyses of the drought stress response in Amygdalus mira (koehne) yü et luroots. - BMC Plant Biology 17: 53.

[2] Carrio, M. M., Villaverde, A. (2001): Protein aggregation as bacterial inclusion bodies is reversible. - FEBS Letters 489: 29-33.

[3] Carrio, M. M., Corchero, J. L., Villaverde, A. (1999): Proteolytic digestion of bacterial inclusion body proteins during dynamic transition between soluble and insoluble forms. Biochim Biophys Acta 1434: 170-176.

[4] Delauney, A. J., Hu, C. A. A., Kishor, P. B. K., Verma, D. P. S. (1993): Cloning of ornithine delta-amino- transferase cDNA from Vigna aconitifolia by 
transcomplementation in Escherichia coli and regulation of proline biosynthesis. Journal of Biological Chemistry 268: 18673-18678.

[5] Dey, A., Samanta, M. K., Gayen, S., Maiti, M. K. (2016): The sucrose non-fermenting 1related kinase 2 genesapk9improves drought tolerance and grain yield in rice by modulating cellular osmotic potential, stomatal closure and stress-responsive gene expression. - BMC Plant Biology 16: 158.

[6] Do, T. H., Jacobs, M., Angenon, G., Hermans, C., Tran, T. T., Son, L. V., Roosens, N. H. (2003): Proline accumulation and $\Delta^{1}$-pyrroline-5-carboxylate synthetase gene properties in three rice cultivars differing in salinity and drought tolerance. - Plant Science 165: 1059-1068.

[7] Ginzberg, I., Stein, H., Kapulnik, Y., Szabados, L., Strizhov, N., Schell, J., Koncz, C., Zilberstein, A. (1998): Isolation and characterization of two different cDNAs of $\Delta^{1}$ pyrroline-5-carboxylate synthase in alfalfa, transcriptionally induced upon salt stress. Plant Molecular Biology 38: 755-764.

[8] Guan, C. F., Ji, J., Guan, W. Z., Feng, Y. H., Li, X. Z., Jin, C., Li, J., Wang, Y. R., Wang, G. (2014): A Lycium chinense-derived P5CS-like gene is regulated by water deficitinduced endogenous abscisic acid and overexpression of this gene enhances tolerance to water deficit stress in Arabidopsis. - Molecular Breeding 34: 1109-1124.

[9] Hu, C. A. A., Delauney, A. J., Verma, D. P. S. (1992): A bifunctional enzyme ( $\Delta^{1}-$ pyrroline-5- carboxylate synthetase) catalyzes the first two steps in proline biosynthesis in plants. - Proceedings of National Academy of Science of the United States of America 89: 9354-9358.

[10] Jain, R., Chandra, A., Venugopalan, V. K., Solomon, S. (2015): Physiological changes and expression of $S O D$ and P5CS genes in response to water deficit in sugarcane. - Sugar Tech 17: 276-282.

[11] Kautz, B., Noga, G., Hunsche, M. (2015): PEG and drought cause distinct changes in biochemical, physiological and morphological parameters of apple seedlings. - Acta Physiologiae Plantarum 37: 1-6.

[12] Kishor, P. B. K., Hong, Z., Miao, G. H., Hu, C. A. A., Verma, D. P. S. (1995): Over expression of $\Delta^{1}$-pyrroline-5- carboxylate synthetase increase proline production and confers osmotolerance in transgenic plants. - Plant Physiology 108: 1387-1394.

[13] Kishor, P. B. K., Sangam, S., Amrutha, R. N., Laxmi, P. S., Naidu, K. R., Rao, K. R. S. S., Rao, S., Reddy, K. J., Theriappan, P., Sreenivasulu, N. (2005): Regulation of proline biosynthesis, degradation, uptake and transport in higher plants: its implications in plant growth and abiotic stress tolerance. - Current Science 88: 424-438.

[14] Krasensky, J., Jonak, C. (2012): Drought, salt, and temperature stress-induced metabolic rearrangements and regulatory networks. - Journal of Experimental Botany 63: 15931608.

[15] Kuzuoglu-Ozturk, D., Cebeci, Y. O., Akpinar, B. A., Mitou, G., Korkmaz, G., Gozuacik, D., Budak, H. (2012): Autophagy-related gene, $\operatorname{TdAtg} 8$, in wild emmer wheat plays a role in drought and osmotic stress response. - Planta 236: 1081-1092.

[16] Li, Y. R., Yang, L. T. (2015): Sugarcane agriculture and sugar industry in China. - Sugar Tech 17: 1-8.

[17] Maruthasalam, S., Kalpana, K., Kumar, K. K., Loganathan, M., Poovannan, K., Raja, J. A. J., Kokiladevi, E., Samiyappan, R., Sudhakar, D., Balasubramanian, P. (2007): Pyramiding transgenic resistance in elite indica rice cultivars against the sheath blight and bacterial blight. - Plant Cell Reports 26: 791-804.

[18] McManus, M. T., Burgess, E. P. J., Philip, B., Watson, L. M., Laing, W. A., Voisey, C. R., White, D. W. R. (1999): Expression of the soybean (Kunitz) trypsin inhibitor in transgenic tobacco: Effects on larval development of Spodoptera litura. - Transgenic Research 8: 383-395. 
[19] Montalbán, N. G., Fruitós, E. G., Ventura, S., Arís, A., Villaverde, A. (2006): The chaperone DnaK controls the fractioning of functional protein between soluble and insoluble cell fractions in inclusion body-forming cells. - Microbial Cell Factories 5: 26.

[20] Nahálka, J., Mislovičová, D., Kavcová, H. (2009): Targeting lectin activity into inclusion bodies for the characterisation of glyco-proteins. - Molecular BioSystems 5: 819-821.

[21] Niu, J. Q., Wang, A. Q., Huang, J. L., Yang, L. T., Li, Y. R. (2015): Isolation, characterization and promoter analysis of cell wall invertase gene socin1, from sugarcane (Saccharum spp.). - Sugar Tech 17: 65-76.

[22] Ortega, C. O. S., Alfaro, A. E. O., Agüero, J. A. R., Santacruz, G. A. A., Bremont, J. F. J. (2008): Salt stress increases the expression of P5CS gene and induces proline accumulation in cactus pear. - Plant Physiology and Biochemistry 46: 82-92.

[23] Ozturk, D. K., Yalcinkaya, O. C., Akpinar, B. A., Mitou, G., Korkmaz, G., Gozuacik, D., Budak, H. (2012): Autophagy-related gene, TdAtg8, in wild emmer wheat plays a role in drought and osmotic stress response. - Planta 236: 1081-1092.

[24] Parrott, D., Yang, L., Shama, L., Fischer, A. M. (2005): Senescence is accelerated, and several proteases are induced by carbon "feast" conditions in barley (Hordeum vulgare L.) leaves. - Planta 222: 989-1000.

[25] Pereira, C. S., Costa, D. S. D., Teixeira, J., Pereira, S. (2005): Organ-specific distribution and subcellular localisation of ascorbate peroxidase isoenzymes in potato (Solanum tuberosum L.) plants. - Protoplasma 226: 223-230.

[26] Phan, T. T., Sun, B., Niu, J. Q., Tan, Q. L., Li, J., Yang, L. T., Li, Y. R. (2016): Overexpression of sugarcane gene SoSnRK2.1 confers drought tolerance in transgenic tobacco. - Plant Cell Reports 35: 1891-1905.

[27] Porcel, R., Azcón, R., Lozano, J. M. R. (2004): Evaluation of the role of genes encoding for $\Delta^{1}$-pyrroline-5-carboxylate synthetase (P5CS) during drought stress in arbuscular mycorrhizal Glycine max and Lactuca sativa plants. - Physiological and Molecular Plant Pathology 65: 211-221.

[28] Pruvot, G., Cuing, S., Peltier, G., Rey, P. (1996): Characterization of a novel droughtinduced 34-kDa protein located in the thylakoids of Solanum tuberosum L. plants. Planta 198: 471-479.

[29] Qiao, X. Q., Wang, P. H., Shi, G. X., Yang, H. Y. (2015): Zinc conferred cadmium tolerance in Lemna minor L. via modulating polyamines and proline metabolism. - Plant Growth Regulation 77: 1-9.

[30] Romman, S. M. A., Ammari, T. G., Irshaid, L. A., Salameh, N. M., Hasan, M. K., Hasan, H. S. (2011): Cloning and expression patterns of the HvP5CS gene from barley (Hordeum vulgare). - Journal of Food, Agriculture \& Environment 9: 279-284.

[31] Ruan, L. T., Zheng, R. C., Zheng, Y. G. (2016): A novel amidase from Brevibacterium epidermidis ZJB-07021: gene cloning, refolding and application in butyrylhydroxamic acid synthesis. - Journal of Indian Microbiology and Biotechnology 43: 1071-1083.

[32] Sahdev, S., Khattar, S. K., Saini, K. S. (2008): Production of active eukaryotic proteins through bacterial expression systems: a review of the existing biotechnology strategies. Molecular and Cell Biochemistry 307: 249-264.

[33] Saibi, W., Feki, K., Yacoubi, I., Brini, F. (2015): Bridging between proline structure, functions, metabolism, and involvement in organism physiology. - Applied Biochemistry and Biotechnology 176: 2107-2119.

[34] Sorensen, H. P., Mortensen, K. K. (2005): Soluble expression of recombinant proteins in the cytoplasm of Escherichia coli. - Microbial Cell Factories 4: 1-8.

[35] Su, M., Li, X. F., Ma, X. Y., Peng, X. J., Zhao, A. G., Cheng, L. Q., Chen, S. Y., Liu, G. S. (2011): Cloning two P5CS genes from bioenergy sorghum and their expression profiles under abiotic stresses and MeJA treatment. - Plant Science 181: 652-659.

[36] Subramanyam, K., Arun, M., Mariashibu, T. S., Theboral, J., Rajesh, M., Singh, N. K., Manickavasagam, M., Ganapathi, A. (2012): Overexpression of tobacco osmotin (Tbosm) 
in soybean conferred resistance to salinity stress and fungal infections. - Planta 236: 1909-1925.

[37] Wan, S. B., Wang, W., Luo, M., Huang, W. D., Yin, J. Y., Zhan, J. C. (2010): cDNA Cloning, prokaryotic expression, polyclonal antibody preparation of the Auxin-Binding Protein 1 gene from grape berry. - Plant Molecular Biology Reporter 28: 373-380.

[38] Wang, F., Tong, W., Zhu, H., Kong, W., Peng, R., Liu, Q., Yao, Q. (2016): A novel $\mathrm{Cys}_{2} / \mathrm{His}_{2}$ zinc finger protein gene from sweet potato, $i b Z F P 1$, is involved in salt and drought tolerance in transgenic Arabidopsis. - Planta 243: 783-797.

[39] Wang, S., Zhang, K. K., Huang, X., Fan, Y. J., Yang, L. T., Li, Y. R. (2015): Cloning and functional analysis of thylakoidal ascorbate peroxidase (TAPX) gene in sugarcane. Sugar Tech 17: 356-366.

[40] Wei, C., Cui, Q., Zhang, X. Q., Zhao, Y. Q., Jia, G. X. (2016): Three P5CS genes including a novel one from Lilium regale play distinct roles in osmotic, drought and salt stress tolerance. - Journal of Plant Biology 59: 456-466.

[41] Xue, Z., Chao, Y., Wang, D., Wang, M., Qian, S. (2011): Overexpression of a recombinant amidase in a complex auto-inducing culture: purification, biochemical characterization, and regio-and stereoselectivity. - Journal of Indian Microbiology and Biotechnology 38: 1931-1938.

[42] Yu, T. A., Chiang, C. H., Wu, H. W., Li, C. M., Yang, C. F., Chen, J. H., Chen, Y. W., Yeh, S. D. (2011): Generation of transgenic watermelon resistant to Zucchini yellow mosaic virus and Papaya ringspot virus type W. - Plant Cell Reports 30: 359-371.

[43] Zheng, L. L., Dang, Z. H., Li, H. Y., Zhang, H. R., Wu, S. B., Wang, Y. C. (2014): Isolation and characterization of a $\Delta^{1}$-pyrroline-5-carboxylate synthetase (NtP5CS) from Nitraria tangutorum Bobr. and functional comparison with its Arabidopsis homologue. Molecular Biology Reports 41: 563-572.

[44] Zhou, H., Qian, J., Zhao, M. D., Li, F., Tong, W., Li, L., Fang, R. J., Zhao, W. G., Kim, H. J. (2016): Cloning and sequence analysis of the $\Delta^{1}$-pyrroline-5-carboxylate synthase gene (MP5CS) from mulberry (Morus alba) and patterns of MP5CS gene expression under abiotic stress conditions. - The Journal of Horticultural Science and Biotechnology 91: 100-108.

[45] Zhu, F., Xu, M. Y., Wang, S. D., Jia, S. D., Zhang, P., Lin, H. H., Xi, D. H. (2012): Prokaryotic expression of pathogenesis related protein 1 gene from Nicotiana benthamiana: antifungal activity and preparation of its polyclonal antibody. - Biotechnol Letters 34: 919-924. 